BMJ Paediatrics Open

\title{
Health-related marketing messages on product labels of commercial infant and toddler food packaging in Australia: a cross-sectional audit
}

\author{
Lucy Simmonds (D) , ${ }^{1}$ Aimee L Brownbill (D) , ${ }^{1,2,3}$ Anthea Zee, ${ }^{4}$ \\ Merryn J Netting (D) ${ }^{1,3}$
}

To cite: Simmonds $L$, Brownbill AL, Zee A, et al. Health-related marketing messages on product labels of commercial infant and toddler food packaging in Australia: a cross-sectional audit. BMJ Paediatrics Open 2021;5:e001241. doi:10.1136/ bmjpo-2021-001241

\section{- Additional supplemental material is published online only. To view, please visit the} journal online (http://dx.doi.org/ 10.1136/bmjpo-2021-001241).

Received 29 July 2021 Accepted 27 October 2021

Check for updates

(C) Author(s) (or their employer(s)) 2021. Re-use permitted under CC BY-NC. No commercial re-use. See rights and permissions. Published by BMJ.

${ }^{1}$ Women and Kids; Health Policy Centre, South Australian Health and Medical Research Institute, Adelaide, South Australia,

Australia

${ }^{2}$ Foundation for Alcohol Research and Education, Canberra, Canberra, Australia ${ }^{3}$ School of Medicine; School of Public Health, The University of Adelaide, Adelaide, South Australia, Australia

${ }^{4}$ College of Nursing and Health Sciences, Flinders University of South Australia, Adelaide, South Australia, Australia

Correspondence to Dr Merryn J Netting; merryn. netting@sahmri.com

\section{ABSTRACT}

Background Proper nutrition in early childhood is essential to ensure optimal growth and development. Use of 'better-for-you' features on food packaging position products as healthier for children. This study aims to systematically explore the use of better-for-you labelling on infant and toddler food packaging.

Methods A cross-sectional audit of health and nutrition claims, text and images used as 'better-for-you' features present on infant and toddler food packaging. Data on infant and toddler food packaging were collected from five large grocery stores in Adelaide, Australia in 2019. The content of 282 unique commercial products $(n=215$ infant foods, $n=67$ toddler foods) were analysed for explicit and implicit features positioning them as better-for-you, including health and nutrition claims as well as text and images representing 'natural.'

Results At least one feature of better-for-you positioning was identified on all food packaging coded. All products had characteristics coded as 'natural'. Almost one-fifth $(17 \%)$ of the products included statements in addition to mandatory allergen labelling that their products were 'free from' certain allergens, or gluten. One-third of the labels had statements related to enhancing development of taste, oro-motor skills and other aspects of childhood development. Of the fruit and vegetable-based infant foods displaying a sugar statement suggesting a low sugar content, $85 \%$ were sweetened with fruit puree.

Conclusions The use of better-for-you features on infant and toddler food packaging is common and pervasive. Allergen-free and developmental claims are being used to position infant and toddler foods as better-for-you. Regulation of toddler food products separately from adult food is required, as is tighter regulation of the appropriate use of sugar and fruit puree statements on infant and toddler food packaging.

\section{INTRODUCTION}

Proper nutrition in early childhood is essential to ensure optimal growth and development. The early complementary feeding period influences longer-term dietary patterns and taste preferences, and poor eating habits can lead to both overnutrition and undernutrition, and non-communicable diseases, such

\section{What is known about the subject}

There is a mismatch between the nutritional characteristics of commercial infant and toddler foods and infant feeding guidelines. Regulated health and nutrition content claims and non-regulated wellness messaging are commonly used on unhealthy products, contributing to consumers believing these products are 'better-for-you'. Advertising and packaging messages suggesting commercial infant foods are healthier than their nutrient content have been observed in the UK and Taiwan.

\section{What this study adds}

The use of better-for-you features on infant and toddler foods is common and pervasive. Allergenfree and developmental claims are being used to position infant and toddler foods as better-for-you. Regulation of toddler food products separately from adult food is required, as is tighter regulation of the appropriate use of sugar and fruit puree statements on infant and toddler food packaging.

as obesity and iron deficiency. ${ }^{1}$ Infant feeding guidelines promote breast feeding and introduction to a diversity of nutritious complementary foods at around 6 months of age when the infant is developmentally ready. ${ }^{2}$

While home-prepared foods are encouraged, commercial infant and toddler foods are a rapidly expanding market sector now estimated to be worth US $\$ 8$ billion per year in the USA alone. ${ }^{3}$ We have previously demonstrated a mismatch between the nutritional and textual properties of commercially available infant and toddler foods and national and international infant feeding guidelines. ${ }^{4}$ Of particular concern is the rapid expansion in the range and types of toddler 'snack foods', which are mostly highly processed, discretionary foods of poor nutritional value. ${ }^{45}$ 
Additionally, many infant foods come in pouches, which may be consumed by sucking from a spout rather than eating with a spoon. With this mode of feeding, there is a risk of delayed development of essential self-feeding skills and appetite dysregulation. ${ }^{6}$

Most countries have specific regulations for the mandatory labelling requirements for infant foods, including nutritional content. In Australia and New Zealand, this falls under the regulatory jurisdiction of Food Standards Australia New Zealand (FSANZ) with different regulations for infants (4-12 months) and toddlers (over 12 months). Compositional requirements for Foods for Infants are outlined in FSANZ Standard 2.9.2 with specific requirements for iron and vitamin $\mathrm{C}$ fortification, restrictions on sodium content and textural requirements for foods produced for infants. ${ }^{7}$ Requirements for toddlers are described in the same schedule as for adults, Schedule 4-Nutrition, health and related claims. ${ }^{8}$ For toddler foods, this is concerning because toddlers have specific growth and developmental needs that are not addressed in Schedule 4.

Additional to regulated labelling information, manufacturers may use non-regulated marketing messaging on product labels to promote purchase. Non-regulated marketing can include wellness messaging that alludes to a product being healthy or nutritious, or a comparatively healthier option, which are not regulated as health and nutrition content claims. ${ }^{9}$ The use of both regulated health and nutrition content claims and nonregulated wellness messaging are commonly used on unhealthy products and can contribute to a 'health halo' effect, whereby consumers consider these products to be healthy or 'better-for-you'. ${ }^{10}$ Better-for-you labelling features employ explicit and implicit messaging such as text, images, colours or symbols on packaging that claim or imply that a product has health-related benefits or is a healthier option than a non-specified competitor product or even home-prepared options. Packaging and advertising messages suggesting commercial infant foods are healthier than their actual nutrient content indicate have been observed in the UK, ${ }^{11}$ and Taiwan. ${ }^{12}$ This is of particular concern as foods consumed by infants and toddlers can influence their development, taste preferences and lifelong health.

Here, we describe health and nutrient claims and other better-for-you labelling on infant and toddler foods currently sold in Australia. We take a comprehensive approach in capturing both regulated health and nutrient content claims as well as other marketing on labels that may result in a health halo. Understanding the messaging communicated to parents and caregivers who are purchasing foods for their young children is important to inform future regulatory guidelines for labelling of infant and toddler foods.

\section{Infant and Toddler Food}

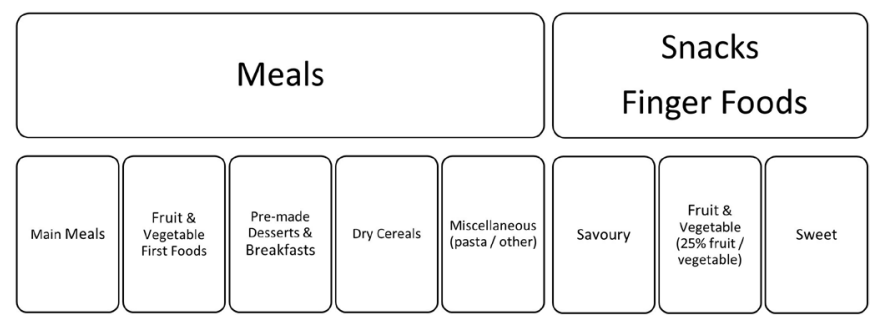

Figure 1 Classification of infant and toddler foods. Meals were divided into main meals, fruit and vegetable first foods, desserts and breakfasts, dry cereals (savoury or sweet), or miscellaneous other. Snacks and finger foods were classified as savoury (starch or legume based and with a bland or savoury flavour profile), fruit and vegetable based, or sweet (fruit-flavoured with a sweet flavour profile). Foods were further classified as meals or snacks/finger foods, as per Tedstone et $\mathrm{al}^{13}$ and subcategorised based on Moumin et $a /{ }^{4}$ products with $>25 \%$ fruit or vegetable ingredients were classified as fruit and vegetable-based finger foods.

\section{METHODS}

We conducted an audit of packaging for infant and toddler foods available in South Australian grocery stores in 2019. We used a convenience sampling method, selecting five large grocery stores representing three nation-wide retailers (Coles, Woolworths and Aldi) along with two independent retailers (Foodland and Drakes). We photographed all infant and toddler food products denoted on the package as suitable for ages 4-24 months sold in the baby food and frozen food aisles. Infant formula was excluded as it is covered by a different set of FSANZ's regulatory standards.

\section{Food categorisation}

Using information on the package, products were classified as infant foods (4-12 months) or toddler foods (>12 months). Foods were further classified as per Tedstone $e t$ $a l^{13}$ and subcategorised based on Moumin et al (figure 1).

\section{Data coding and analysis}

A coding framework to capture health and nutritionrelated marketing developed by Brownbill et at was adapted for infant and toddler food products, using regulated nutrient content claims and general health (claims that imply that the food product has a health-related effect, such as 'good for baby's digestion') and high level health (claims about a nutrient in a food and its relationship to a serious disease, such as "wholegrains to reduce risk of heart disease') claims defined and regulated by FSANZ, and nutrition and health claims. The coding framework comprised 25 categories with 125 individual codes (online supplemental appendix 1). Each product label was coded by two researchers independently for the presence/absence of marketing features. Where there was disagreement, a consensus was reached by discussion with a third team member. To validate the coding of the primary coders, a random sample of $10 \%$ was 
Table 1 Health, nutrition and other better-for-you claims in commercial infant and toddler foods

\begin{tabular}{|c|c|c|c|c|c|c|}
\hline \multirow[b]{2}{*}{ Category/claim } & \multicolumn{2}{|c|}{$\begin{array}{l}\text { All products } \\
\mathrm{N}=\mathbf{2 8 2}\end{array}$} & \multicolumn{2}{|c|}{$\begin{array}{l}\text { Infant products } \\
\mathrm{N}=\mathbf{2 1 5}\end{array}$} & \multicolumn{2}{|c|}{$\begin{array}{l}\text { Toddler products } \\
\mathrm{N}=67\end{array}$} \\
\hline & $\mathbf{N}$ & $\%$ & $\mathbf{N}$ & $\%$ & $\mathbf{N}$ & $\%$ \\
\hline Allergen free and gluten free & 47 & 16.7 & 31 & 14.4 & 16 & 23.9 \\
\hline Allergen free claim only & 9 & 3.2 & 6 & 2.8 & 3 & 4.5 \\
\hline Gluten free claim only & 21 & 7.4 & 17 & 7.9 & 4 & 6.0 \\
\hline Vegetarian/vegan & 22 & 7.8 & 15 & 7.0 & 7 & 10.4 \\
\hline Sugar & 173 & 61.3 & 147 & 68.4 & 26 & 38.8 \\
\hline No added sugar & 155 & 55.0 & 137 & 63.7 & 18 & 26.9 \\
\hline No concentrates & 20 & 7.1 & 17 & 7.9 & 3 & 4.5 \\
\hline Natural sugar/sugar from fruit, veg & 36 & 12.8 & 33 & 15.3 & 3 & 4.5 \\
\hline Sodium & 125 & 44.3 & 112 & 52.1 & 13 & 19.4 \\
\hline No added salt & 120 & 42.6 & 111 & 51.6 & 9 & 13.4 \\
\hline Low in salt/sodium & 6 & 2.1 & 2 & 0.9 & 4 & 6.0 \\
\hline Fat & 28 & 9.9 & 13 & 6.0 & 15 & 22.4 \\
\hline No added fat/oil/ transfat/low fat & 7 & 2.5 & 3 & 1.4 & 4 & 6.0 \\
\hline Baked, not fried, air popped & 23 & 8.2 & 10 & 4.7 & 13 & 19.4 \\
\hline Protein & 62 & 22.0 & 52 & 24.2 & 10 & 14.9 \\
\hline in text/image & 55 & 19.5 & 49 & 22.8 & 6 & 9.0 \\
\hline Source of/servings or \% protein & 33 & 11.7 & 25 & 11.6 & 8 & 11.9 \\
\hline Dairy & 64 & 22.7 & 44 & 20.5 & 20 & 29.9 \\
\hline In text/image & 62 & 22.0 & 43 & 20.0 & 19 & 28.4 \\
\hline Servings or \% dairy & 3 & 1.1 & 3 & 1.4 & 0 & 0 \\
\hline Fruits & 156 & 55.3 & 122 & 56.7 & 34 & 50.7 \\
\hline In text/image & 155 & 55.0 & 122 & 56.7 & 33 & 49.3 \\
\hline Servings or $\%$ fruit & 17 & 6.0 & 17 & 7.9 & 0 & 0 \\
\hline Vegetables & 118 & 41.8 & 103 & 47.9 & 15 & 22.4 \\
\hline In text/image & 108 & 38.3 & 95 & 44.2 & 13 & 19.4 \\
\hline Servings or \% veg & 31 & 11.0 & 26 & 12.1 & 5 & 7.5 \\
\hline Grains/cereals & 119 & 42.2 & 89 & 41.4 & 30 & 44.8 \\
\hline In text/image & 114 & 40.4 & 86 & 40.0 & 28 & 41.8 \\
\hline Servings or \% grain & 10 & 3.5 & 8 & 3.7 & 2 & 3.0 \\
\hline Superfoods (fruit/veg/grains) & 96 & 34.0 & 74 & 34.4 & 22 & 32.8 \\
\hline Nutrition & 111 & 39.4 & 81 & 37.7 & 30 & 44.8 \\
\hline Nutritious, nourishing, wholesome & 65 & 23.0 & 47 & 21.9 & 18 & 26.9 \\
\hline Contains nutrients, vitamins, minerals, antioxidants & 45 & 16.0 & 38 & 17.7 & 7 & 10.4 \\
\hline Vitamins (eg, C or B) & 34 & 12.1 & 29 & 13.5 & 5 & 7.5 \\
\hline Iron & 27 & 9.6 & 24 & 11.2 & 3 & 4.5 \\
\hline Calcium & 12 & 4.3 & 11 & 5.1 & * & 1.5 \\
\hline Essential fatty acids (eg, DHA) & 13 & 4.6 & 10 & 4.7 & 3 & 4.5 \\
\hline Fibre & 13 & 4.6 & 7 & 3.3 & 6 & 9.0 \\
\hline Natural & 282 & 100 & 215 & 100 & 67 & 100 \\
\hline 'Natural' & 50 & 17.7 & 41 & 19.1 & 9 & 13.4 \\
\hline Pure or raw & 34 & 12.1 & 26 & 12.1 & 8 & 11.9 \\
\hline Organic/organic symbol & 146 & 51.8 & 109 & 50.7 & 37 & 55.2 \\
\hline Real/fresh or homemade & 63 & 22.3 & 46 & 21.4 & 17 & 25.4 \\
\hline
\end{tabular}


Table 1 Continued

\begin{tabular}{|c|c|c|c|c|c|c|}
\hline \multirow[b]{2}{*}{ Category/claim } & \multicolumn{2}{|c|}{$\begin{array}{l}\text { All products } \\
\mathrm{N}=282\end{array}$} & \multicolumn{2}{|c|}{$\begin{array}{l}\text { Infant products } \\
\mathrm{N}=215\end{array}$} & \multicolumn{2}{|c|}{$\begin{array}{l}\text { Toddler products } \\
\mathrm{N}=67\end{array}$} \\
\hline & $\mathbf{N}$ & $\%$ & $\mathbf{N}$ & $\%$ & $\mathbf{N}$ & $\%$ \\
\hline No additives, preservatives & 252 & 89.4 & 195 & 90.7 & 57 & 85.1 \\
\hline No chemicals, pesticides, GMO & 103 & 36.5 & 77 & 35.8 & 26 & 38.8 \\
\hline Images of nature & 154 & 54.6 & 109 & 50.7 & 45 & 67.2 \\
\hline Good or goodness & 90 & 31.9 & 71 & 33.0 & 19 & 28.4 \\
\hline Health/wellness claims & 49 & 17.4 & 32 & 14.9 & 17 & 25.4 \\
\hline High level health & 0 & 0 & 0 & 0 & 0 & 0 \\
\hline General level health & 7 & 2.5 & 3 & 1.4 & 4 & 6.0 \\
\hline Health/healthy/wellness & 6 & 2.1 & 4 & 1.9 & 2 & 3.0 \\
\hline Gut health/happy tummies & 31 & 11.0 & 22 & 10.2 & 9 & 13.4 \\
\hline Teething claims & 12 & 4.3 & 7 & 3.3 & 5 & 7.5 \\
\hline Development claims & 90 & 31.9 & 57 & 26.5 & 33 & 49.3 \\
\hline Help, improve, assist, encourage & 13 & 4.6 & 11 & 5.1 & 2 & 3.0 \\
\hline Learning/brain/cognition & 2 & 0.9 & * & 0.5 & * & 1.5 \\
\hline Self-feeding & 42 & 14.9 & 26 & 12.1 & 16 & 23.9 \\
\hline Development of tastebuds & 48 & 17.0 & 39 & 18.1 & 9 & 13.4 \\
\hline Development of jaw, mouth & 11 & 3.9 & 3 & 1.4 & 8 & 11.9 \\
\hline General growth, development & 32 & 11.3 & 20 & 9.3 & 12 & 17.9 \\
\hline Adult snack food images* & 69 & 24.5 & 28 & 13.0 & 41 & 61.2 \\
\hline Sweets, chocolate & 7 & 2.5 & 2 & 0.9 & 5 & 7.5 \\
\hline Crisps (puffs, straw, popcorn) & 24 & 8.5 & 13 & 6.0 & 11 & 16.4 \\
\hline Sweet biscuits/cookies & 12 & 4.3 & 5 & 2.3 & 7 & 10.4 \\
\hline Savoury biscuits/crackers & 10 & 3.5 & 4 & 1.9 & 6 & 9.0 \\
\hline Snack bars & 19 & 6.7 & 4 & 1.9 & 15 & 22.4 \\
\hline
\end{tabular}

Bold text represents the overarching claim (eg, 'Sugar' is the overarching claim, with 'No added sugar' sitting below that claim)

${ }^{*}$ Products with images of adult snack foods (crackers, cookies, crisps or sweets) on pack were coded.

DHA, Docosahexaenoic acid; GMO, Genetically modified organisms.

cross-checked by a third team member. Due to the large number of sugar-related claims, a sub-analysis of claims on labels of foods with monosaccharide and disaccharide content of added sugars and honey $>4 \mathrm{~g}$ per $100 \mathrm{~g}$ consistent with Standard 2.9.2-7 (3.d) was conducted as a comparator.

\section{Public and patient involvement}

The premise of this study stems from questions one of our authors was asked by patients about better-for-you features on toddler food packaging.

\section{RESULTS}

The packaging of 282 unique commercial products was coded ( $\mathrm{n}=215$ infant foods and $\mathrm{n}=67$ toddler foods; table 1). Of the infant meals, main meals were the predominant product type $(\mathrm{n}=70)$, followed by desserts and breakfasts $(\mathrm{n}=46)$ and mixed fruit and/or vegetable first food purees $(n=45)$ (table 2). Most of the infant meals were presented in ‘squeeze pouches' (131 of 161).
Of the toddler foods, $80 \%$ were snack foods (extruded puffs flavoured with fruit or vegetable powder, sweet biscuits or rice cakes and fruit and vegetable-containing bars). ${ }^{4}$

All products contained at least one better-for-you feature on the label. The presence of health, nutrition and other better-for-you claims among the study sample are presented in table 1 (infant compared with toddler foods) and table 2 (by food category).

Nutrition and nutrient-related: Over one-third of the packaging $(39 \%)$ promoted positive nutritional qualities. This occurred through general statements that the product was 'nourishing', 'nutritious' or 'wholesome' (23\%), and/or that the product contained 'nutrients', 'vitamins', 'minerals' or 'antioxidants' (16\%).

Macronutrients and core food groups: Products referred to healthy whole foods through descriptors and/or images of fruits (55\%), vegetables (42\%), grains or cereals $(42 \%)$, dairy products $(23 \%)$ and/or protein products (eg, meats, fish, eggs; 22\%). One-third of 


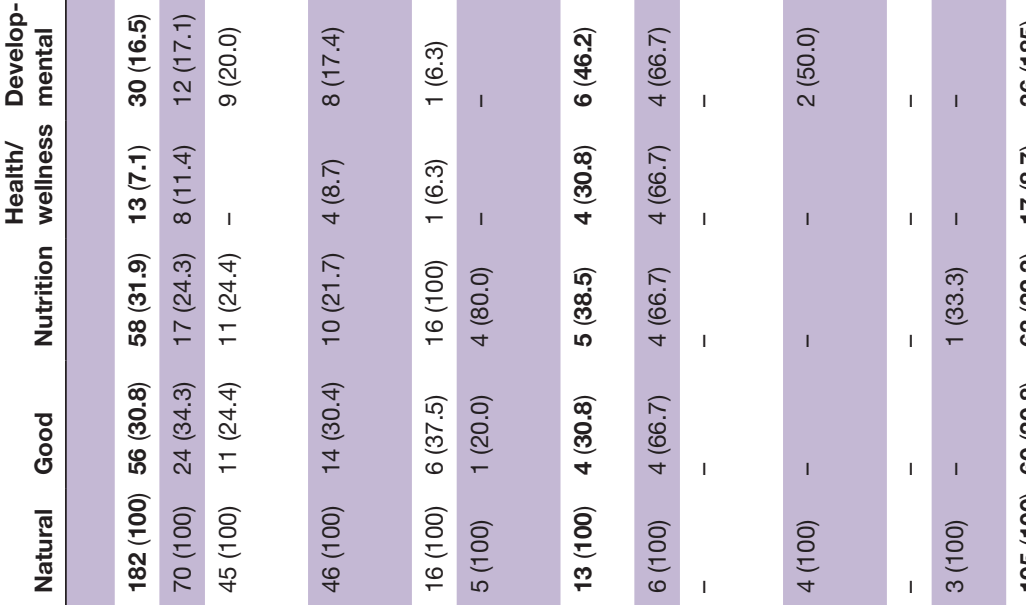

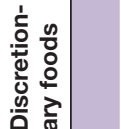

ஸे

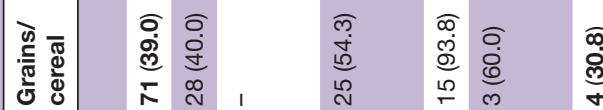

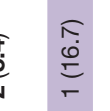

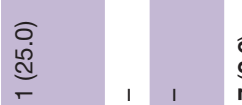

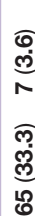

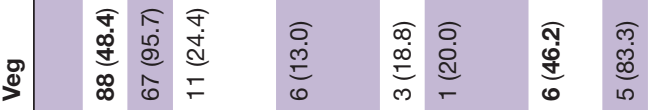

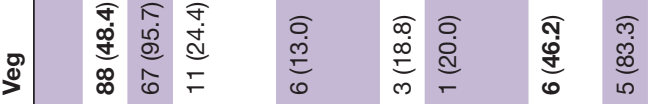

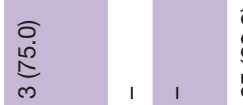

बi

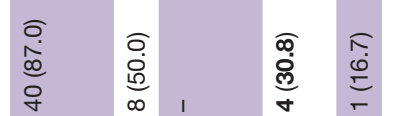

莘

o.
in
n.

感

ल⿸户

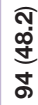

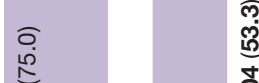

의

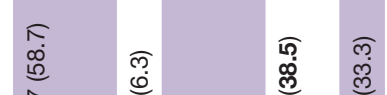

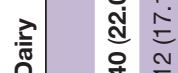

స

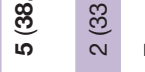

.

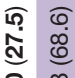

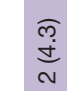

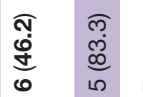

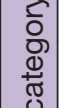

-

응

ลे

स $\widehat{\overline{0}}$

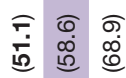

कृ

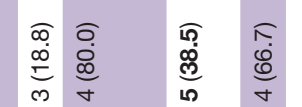

$\frac{\text { 就 }}{0}$

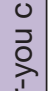

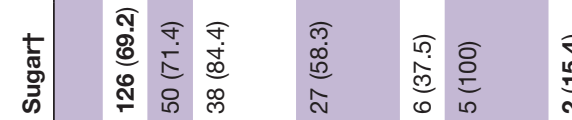

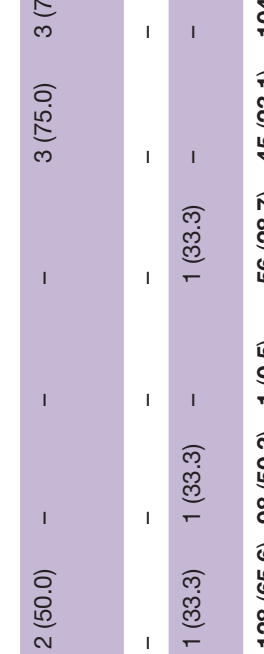

눈

बุ广

$\widehat{\infty} \widehat{0}$

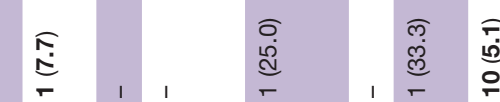

응

क

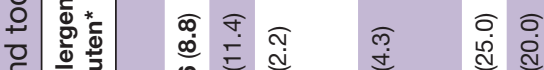

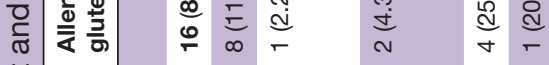

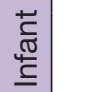

๓ำㅇำ

लु

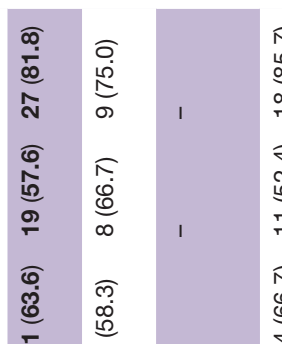

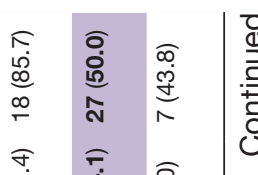

$\frac{0}{3}$

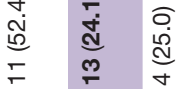

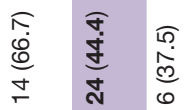

क्ष.

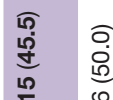

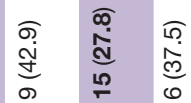

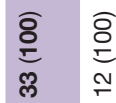

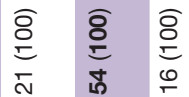

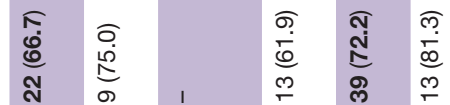

鹿

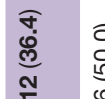

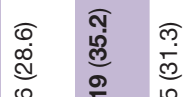

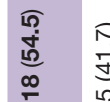

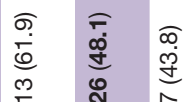

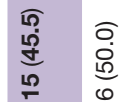

ब.

总

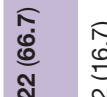

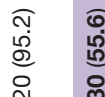

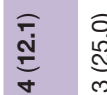

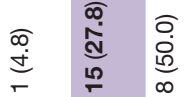

实

$\frac{\sqrt{n}}{\overparen{0}}$

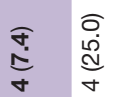

ณฺุ

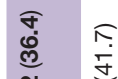

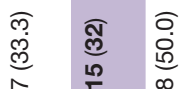

웅

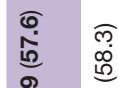

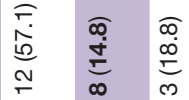

을

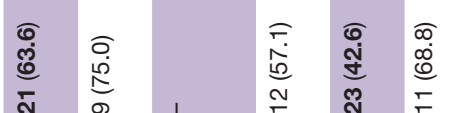




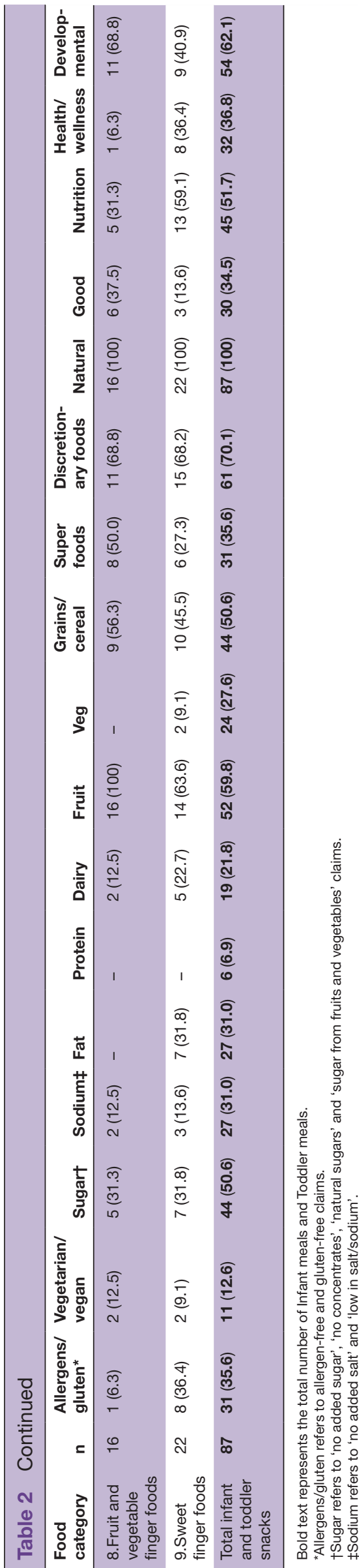

products contained descriptors and/or images of fruits, vegetables or grains recognised as 'superfoods' (34\%).

Sugar, salt and fat: Over half of the products contained statements related to sugar content (61\%), more commonly on infant $(68 \%)$ than toddler foods $(39 \%)$. Sugar statements mostly took the form of 'No added sugar' claims $(55 \%)$ but products also referred to containing 'natural sugar' or sugar from fruit and/ or vegetables $(13 \%)$. Thirty-four $(12 \%)$ products had statements such as 'all sugars are naturally occurring' within the nutritional information panel (NIP). Sugar claims were present on foods with sweet and savoury taste profiles (table 3). Of the fruit and vegetable-based infant foods displaying a sugar statement regarding low sugar content, $85 \%$ were sweetened with fruit puree.

Statements related to salt content were common with $44 \%$ of the labels stating, 'no added salt' or 'low salt' (52\% of infant, $19 \%$ of toddler foods). Less common were statements related to fat content: at $10 \%$ of products, these tended to be insinuated through using terms such as 'baked' or 'not fried' than a 'no' or 'low' fat claim.

Natural: All products had characteristics coded as positioning the product as natural. This most commonly included products stating that they were free from additives or preservatives $(89 \%)$, but it was also common for products to contain images of nature $(55 \%)$, and 'organic' statements/symbols (52\%).

Health and wellness: Of all products coded, 17\% displayed a health or wellness better-for-you feature, more commonly observed among toddler (25\%) than infant foods $(15 \%)$. However, very few were regulated general health claims $(3 \%)$ and none were high level health claims. One in 10 products had a statement related to gut health (eg, 'smile from the inside', 'happy tummies') and a small number claimed to assist with teething (4\%).

Childhood development: Marketing specifically related to child development was present on one-third $(32 \%)$ of the food products. This group of statements was more frequently identified on toddler $(49 \%)$ than infant foods $(27 \%)$. These claims included statements related to development of taste preferences, self-feeding skills, oromotor skills and general development (see figure 2).

Dietary restrictions: Additional to mandatory allergen labelling, $17 \%$ of the products included 'free from' allergen or gluten statements. Eight per cent of the products claimed that the product was suitable for vegetarians or vegans.

Discretionary foods: Thirty-one per cent (82 of 282) of all foods, including $81 \%$ of all toddler foods, were snack or finger foods. Images portraying adult snack foods (eg, bars, protein balls, cookies) were present on $70 \%$ (61 of 87 ) of toddler packaging. Half (44 of 87 ) had a sugar statement on the label, including $71 \%$ (20 of 28) of savoury foods (table 3). A salt statement was present on one-third (31\%; 27 of 87 ) of all snack foods, including $57 \%$ of sweet-flavoured infant snack foods (12 of 21). All snack food packaging had 'natural' statements or images, and one-third had 'goodness' statements or 
Table 3 Sugar claims present on infant and toddler foods by food category N (\%)

\begin{tabular}{|c|c|c|c|c|c|c|c|c|}
\hline \multirow[b]{2}{*}{ Food category } & \multirow[b]{2}{*}{$\mathbf{n}$} & \multirow{2}{*}{$\begin{array}{l}\begin{array}{l}\text { Any sugar } \\
\text { claim }\end{array} \\
\text { n (\%) }\end{array}$} & \multicolumn{3}{|c|}{ Savoury / bland taste profile } & \multicolumn{3}{|c|}{ Sweet taste profile } \\
\hline & & & n (\%) & $\begin{array}{l}\text { g sugars / } 100 \mathrm{~g} \\
\text { median (range) }\end{array}$ & $\begin{array}{l}>4 \mathrm{~g} \text { sugars } \\
/ 100 \mathrm{~g}\end{array}$ & n (\%) & $\begin{array}{l}\text { g sugars / } 100 \mathrm{~g} \\
\text { median (range) }\end{array}$ & $\begin{array}{l}>4 \mathrm{~g} \text { sugars } \\
/ 100 \mathrm{~g}\end{array}$ \\
\hline Infant meals & 182 & $126(69.2)$ & & & & & & \\
\hline 1.Main meals & 70 & $50(71.4)$ & $48(96.0)$ & 2.8 (0.8 to 8.5$)$ & $7(14.5)$ & $2(4.0)$ & 8.7 (6.3 to 11$)$ & $2(100)$ \\
\hline $\begin{array}{l}\text { 2.Fruit and veg } \\
\text { first foods }\end{array}$ & 45 & $38(84.4)$ & $7(18.4)$ & $5.6(1.7$ to 9.1$)$ & $6(85.7)$ & $31(81.5)$ & 11.1 (7.5 to 14.4$)$ & $31(100)$ \\
\hline $\begin{array}{l}\text { 3.Premade } \\
\text { desserts and } \\
\text { breakfasts }\end{array}$ & 46 & $27(58.3)$ & - & - & - & $27(100)$ & 7.8 (4.9 to 15.8$)$ & $27(100)$ \\
\hline 4.Dry cereals & 16 & $6(37.5)$ & 2 (33.3) & 0.5 (0.4 to 1.0$)$ & - & $4(66.6)$ & 2.9 (0.5 to 5.2$)$ & $2(50.0)$ \\
\hline $\begin{array}{l}\text { 5.Misc. }(\text { dry } \\
\text { pasta }(n=4) \text {, } \\
\text { other }(n=1)^{\star}\end{array}$ & 5 & $5(100)$ & $4(80.0)$ & 1.7 (0.3 to 3$)$ & - & - & - & - \\
\hline 1.Main meals & 6 & - & - & - & - & - & - & - \\
\hline $\begin{array}{l}\text { 2.Fruit and veg } \\
\text { first foods }\end{array}$ & - & - & - & - & - & - & - & - \\
\hline $\begin{array}{l}\text { 3.Premade } \\
\text { desserts and } \\
\text { breakfasts }\end{array}$ & 4 & $2(50.0)$ & - & - & - & $2(50.0)$ & 5.3 (5.2 to 5.5$)$ & $2(100)$ \\
\hline 4.Dry cereals & - & - & - & - & - & - & - & - \\
\hline $\begin{array}{l}\text { 5.Misc. (dry } \\
\text { pasta) }\end{array}$ & 3 & $1(33.3)$ & $1(33.3)$ & $3.1(n / a)$ & - & - & - & - \\
\hline $\begin{array}{l}\text { Total infant and } \\
\text { toddler meals }\end{array}$ & 195 & $128(65.6)$ & & & & & & \\
\hline
\end{tabular}

Infant and toddler foods with any sugar claim, by category. Categorised by savoury/bland and sweet taste profiles with median (range) of sugars $\mathrm{g} / 100 \mathrm{~g}$ as per nutritional information panel, and number of foods with sugar content $>4 \mathrm{~g}$ per $100 \mathrm{~g}$ as per Schedule 4 Standard 2.9.2-7.3 (d) if the monosaccharide and disaccharide content of added sugars and honey is more than $4 \mathrm{~g} / 100 \mathrm{~g}$, the word 'sweetened' must be included on the label.

${ }^{*} \mathrm{n}=1$ flavoured tea; not included in table.

images. One-half of all snack foods had statements or images related to general nutrition, and one-third of infant finger foods had statements related to a specific nutrient. Developmental claims were identified in 63\% (54 of 87) of all snack foods (table 1).

\section{DISCUSSION}

Parents and caregivers face a barrage of information when deciding which foods to purchase for their infants and toddlers. Our in-depth analysis of the marketing messages on the packaging of a contemporary sample of Australian commercial infant and toddler foods identified better-for-you features on all food packaging audited. We identified 'natural' statements and/or images on all of these products and half displayed statements related to 'organic' ingredients, even among highly processed foods including extruded snack foods and fruit and vegetable purees in squeeze pouches. This is concerning as, despite the presence of better-for-you features on infant and toddler foods, the nutritional value of commercial infant and toddler foods does not align with feeding guidelines. $^{4614}$

The strengths of our research included the comprehensive sampling of infant and toddler packaging, presented as an age continuum, which extends our description of the nutritional characteristics of Australian infant and toddler foods. ${ }^{4}$ While our work builds on previous studies focusing exclusively on Australian toddler foods 


\section{Taste
preferences

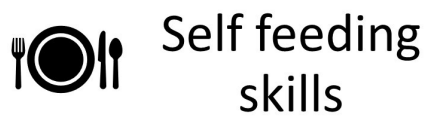

'explore and enjoy simple flavours',

'teach your little one to love their veggies'
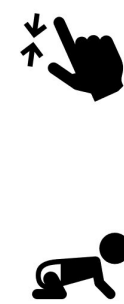

\section{Oro-Motor skills}

\section{General}

promote independence', 'develop pincer grip', 'hand to mouth coordination', 'perfect for little fingers', 'for fearless fingers'

'great way to introduce different textures' 'explore and enjoy simple .. textures'

Figure 2 Examples of childhood development better-for-you features present on infant and toddler food labels.

and toddler formula ${ }^{5}$ or infant foods in Taiwan ${ }^{12}$ and the $\mathrm{UK},{ }^{11}$ our analysis cannot determine whether the betterfor-you features influence how parents and caregivers perceive the infant and toddler food products. Future research should explore how the packaging of these foods is perceived by caregivers and the influence it has on decisions when feeding their children.

We have identified claims used to position infant and toddler foods as better-for-you not previously described, specifically the use of 'allergen free' and 'gluten free' statements. These statements, additional to mandatory allergen labelling, position foods as safe to consume for individuals with food allergies or coeliac disease. While some parental concern about allergen content of commercial foods has been identified, ${ }^{15}$ contemporary infant feeding guidelines encourage regular exposure to food allergens to prevent allergy development, rather than avoidance. ${ }^{16-18}$ For those without diagnosed allergies, the emphasis of 'free from allergens' as a healthier food choice may be harmful if the child is consequently not exposed to common allergens in their usual diet. ${ }^{19}$

Developmental claims, purporting to foster the health and development of the child, were identified on infant and toddler foods, extending the observation from infant and toddler formula. ${ }^{20}{ }^{21}$ We identified childhood development claims on half of the toddler foods and one-quarter of infant foods, including claims related to development of taste preferences (eg, 'ideal for babies refusing foods' usually on products containing vegetables mixed with sweeter foods). There is no evidence that consumption of foods displaying such claims is associated with broader taste preferences, or improved development. On the contrary, current evidence suggests that to improve children's liking of vegetables in the first 5 years of life, repeated exposure to a variety of vegetables of different flavours and textures is vital, ${ }^{22}$ including serving plain-vegetables-first approach. In our audit, there were no single vegetable dishes, and most of the vegetable-based foods contained apple or sweet-tasting vegetables, such as carrots and sweet potatoes. Increased parental awareness of the need for repeated exposure to vegetables would create a new opening in the market for manufacturers to develop single vegetable foods scarcely available at present.

Further, development claims around oro-motor skills (eg, 'right texture for chewing which is important for speech development') were commonly observed on toddler snack foods, many of which were highly processed extruded puffs. These foods dissolve easily in the mouth, and as such are unlikely to present a choking hazard. As infants learn to chew and swallow a variety of foods, they should progress from meltable foods to those that are more challenging to chew and swallow. ${ }^{23}{ }^{24}$ However, in this audit many meltable foods were marketed for toddlers who should be learning to consume more challenging foods.

We observed both regulated and non-regulated claims being used in misleading ways. Despite regulation of the term 'no added sugar', this claim is permissible for infant and toddler fruit and vegetable-based puree foods with high free sugars content. Additionally, nonregulated claims suggesting a low sugar content such as 'natural sugars' and 'no concentrates' are frequently used on these products. In our audit, $85 \%$ of the fruit and vegetable-based infant foods displayed a sugar statement suggesting a low sugar content, despite being sweetened with fruit puree, consistent with our nutritional survey, ${ }^{4}$ and surveys internationally. ${ }^{1125-27}$ One option for food regulators is to classify fruit puree as 'added sugar', similar to fruit juice and concentrates, as per Swan et al's definition that expands the WHO's definition for free sugars to fruit puree and pastes. ${ }^{28}$ 
Moreover, we observed potentially misleading salt claims in close to half of all products, including in onethird of the sweet infant fruit purees where salt is not expected to be an ingredient. This may mislead parents as the 'no added salt' claim may give the product a health halo, potentially encouraging parents to assume that the product is healthier than it is due to its low sodium content. This misconception is a distinct possibility as focus group work indicates that mothers are mindful of sodium content. ${ }^{15}$ Compared with infant snack foods, salt claims were observed less frequently on the toddler snack foods $(60 \%$ of the savoury and sweet infant snacks, compared with $15 \%$ of the toddler snacks) as toddler foods are regulated under the adult nutrition content with a larger (adult) sodium allowance.

While evidence in this area is scant, given the tight regulation of infant formula, parents may incorrectly assume that there is similar regulation of nutritional content of commercial infant and toddler foods (often co-located with infant formula in the retail setting) and that these foods are nutritionally equivalent to (or better than) home cooked foods. ${ }^{1529} 30$ This is particularly an issue for toddler snack foods as they may also consumed by infants, even though they are labelled for 12 months plu. The regulation of nutritional content and wellness better-for-you features of toddler foods should be separated from adult food products, given the physiological size difference between toddlers and adults and the importance of nutrition in these early years. Understanding the messaging communicated to parents purchasing foods for their babies is important to inform appropriate development of guidelines for labelling of infant and toddler food packaging, and, importantly, the translation of these guidelines into specific advice for parents and other consumers.

\section{CONCLUSION}

Nutrition and wellness better-for-you features are common and pervasive on infant and toddler food labels. We identified allergen-free and developmental claims used to position infant and toddler foods as better-for-you, despite these foods largely being highly processed. Regulation of toddler food products separately from adult food is required, as is tighter regulation of the appropriate use of sugar and fruit puree statements on infant and toddler foods.

Acknowledgements We gratefully acknowledge the assistance of Tyla Hunt and Michaella Fancsali in data coding in early phases of this study and Professors Tim Green and Maria Makrides for critical review of the manuscript

Contributors Study concept and design: MJN, LS, ALB and AZ. Drafting the manuscript: MJN, LS and ALB.Comment and approval of the final draft of the manuscript: MJN, LS, ALB and AZ. Statistical expertise: MJN. Obtained funding: The present analyses were not funded. Administrative, technical or material support: MJN, LS, ALB and AZ. MJN acts as the guarantor.

Funding The authors have not declared a specific grant for this research from any funding agency in the public, commercial or not-for-profit sectors.

Competing interests None declared.
Patient consent for publication Not applicable.

Provenance and peer review Not commissioned; externally peer reviewed.

Data availability statement Data are available on reasonable request. Data may be shared on reasonable request via email (Merryn.Netting@sahmri.com).

Supplemental material This content has been supplied by the author(s). It has not been vetted by BMJ Publishing Group Limited (BMJ) and may not have been peer-reviewed. Any opinions or recommendations discussed are solely those of the author(s) and are not endorsed by BMJ. BMJ disclaims all liability and responsibility arising from any reliance placed on the content. Where the content includes any translated material, BMJ does not warrant the accuracy and reliability of the translations (including but not limited to local regulations, clinical guidelines, terminology, drug names and drug dosages), and is not responsible for any error and/or omissions arising from translation and adaptation or otherwise.

Open access This is an open access article distributed in accordance with the Creative Commons Attribution Non Commercial (CC BY-NC 4.0) license, which permits others to distribute, remix, adapt, build upon this work non-commercially, and license their derivative works on different terms, provided the original work is properly cited, appropriate credit is given, any changes made indicated, and the use is non-commercial. See: http://creativecommons.org/licenses/by-nc/4.0/.

ORCID iDs

Lucy Simmonds http://orcid.org/0000-0002-4795-5141

Aimee L Brownbill http://orcid.org/0000-0002-3368-3907

Merryn J Netting http://orcid.org/0000-0002-0642-9145

\section{REFERENCES}

1 Zalewski BM, Patro B, Veldhorst M, et al. Nutrition of infants and young children (one to three years) and its effect on later health: a systematic review of current recommendations (EarlyNutrition project). Crit Rev Food Sci Nutr 2017;57:489-500.

2 National Health and Medical Research Council. Infant feeding guidelines. Canberra, 2012.

3 Euromonitor International. Baby food in the US, 2019.

4 Moumin NA, Green TJ, Golley RK, et al. Are the nutrient and textural properties of Australian commercial infant and toddler foods consistent with infant feeding advice? Br J Nutr 2020;124:754-60.

5 McCann JR, Russell CG, Campbell KJ, et al. Nutrition and packaging characteristics of toddler foods and milks in Australia. Public Health Nutr 2021;24:1153-65.

6 Koletzko B, Bührer C, Ensenauer R, et al. Complementary foods in baby food pouches: position statement from the nutrition Commission of the German Society for pediatrics and adolescent medicine (DGKJ, e.V.). Mol Cell Pediatr 2019;6:2.

7 Food standards Australia New Zealand. Australia New Zealand food standards code. standard 2.9.2 food for infants. Canberra, 2016.

8 Food standards Australia New Zealand. Australia New Zealand food standards code. schedule 4. nutrition, health and related claims. Canberra, 2016.

9 Brownbill AL, Miller CL, Braunack-Mayer AJ. Industry use of 'betterfor-you' features on labels of sugar-containing beverages. Public Health Nutr 2018;21:3335-43.

10 Kaur A, Scarborough P, Rayner M. A systematic review, and metaanalyses, of the impact of health-related claims on dietary choices. Int J Behav Nutr Phys Act 2017;14:1-17.

11 Crawley H, Westland S. Baby foods in the UK. A review of commercially produced jars and pouches of baby foods marketed in the UK. (first steps nutrition trust.

12 Koo Y-C, Chang J-S, Chen YC. Food claims and nutrition facts of commercial infant foods. PLoS One 2018;13:e0191982.

13 Tedstone A, Nicholas J, MacKinlay B. Foods and drinks aimed at infants and young children: evidence and opportunities for action: June. London: Public Health England, 2019.

14 Padarath S, Gerritsen S, Mackay S. Nutritional aspects of commercially available complementary foods in New Zealand Supermarkets. Nutrients 2020;12:2980.

15 Maslin K, Galvin AD, Shepherd S. A qualitative study of mothers perceptions of weaning and the use of commercial infant food in the United Kingdom. Matern Pediatr Nutr 2015;1.

16 Halken S, Muraro A, de Silva D, et al. EAACl guideline: preventing the development of food allergy in infants and young children (2020 update). Pediatr Allergy Immunol 2021;32:843-58.

17 Joshi PA, Smith J, Vale S, et al. The Australasian Society of clinical immunology and allergy infant feeding for allergy prevention guidelines. Med J Aust 2019;210:89-93. 
18 Fleischer DM, Chan ES, Venter C, et al. A consensus approach to the primary prevention of food allergy through nutrition: guidance from the American Academy of allergy, asthma, and immunology; American College of allergy, asthma, and immunology; and the Canadian Society for allergy and clinical immunology. J Allergy Clin Immunol Pract 2021;9:22-43.

19 Netting MJ, Gold MS, Palmer DJ. Low allergen content of commercial baby foods. J Paediatr Child Health 2020;56:1613-7.

20 Berry NJ, Gribble KD. Health and nutrition content claims on websites advertising infant formula available in Australia: a content analysis. Matern Child Nutr 2017;13. doi:10.1111/mcn.12383. [Epub ahead of print: 14 Oct 2016].

21 Pomeranz JL, Romo Palafox MJ, Harris JL. Toddler drinks, formulas, and milks: labeling practices and policy implications. Prev Med 2018;109:11-16.

22 Bell LK, Gardner C, Kumar S, et al. Identifying opportunities for strengthening advice to enhance vegetable liking in the early years of life: qualitative consensus and triangulation methods. Public Health Nutr 2021:1-16.

23 Le Révérend BJD, Edelson LR, Loret C. Anatomical, functional, physiological and behavioural aspects of the development of mastication in early childhood. Br J Nutr 2014;111:403-14.
24 Cichero JAY. Unlocking opportunities in food design for infants, children, and the elderly: understanding milestones in chewing and swallowing across the lifespan for new innovations. J Texture Stud 2017;48:271-9.

25 Garcia AL, McLean K, Wright CM. Types of fruits and vegetables used in commercial baby foods and their contribution to sugar content. Matern Child Nutr 2016;12:838-47.

26 Garcia AL, Curtin L, Ronquillo JD, et al. Changes in the UK baby food market surveyed in 2013 and 2019: the rise of baby snacks and sweet/savoury foods. Arch Dis Child 2020;105:1162-6.

27 Dunford E, Louie JCY, Byrne R, et al. The nutritional profile of baby and toddler food products sold in Australian Supermarkets. Matern Child Health J 2015;19:2598-604.

28 Swan GE, Powell NA, Knowles BL, et al. A definition of free sugars for the UK. Public Health Nutr 2018;21:1636-8.

29 Abrams KM, Evans C, Duff BRL. Ignorance is bliss. How parents of preschool children make sense of front-of-package visuals and claims on food. Appetite 2015;87:20-9.

30 Chien T-Y, Chien Y-W, Chang J-S, et al. Influence of Mothers' Nutrition Knowledge and Attitudes on Their Purchase Intention for Infant Cereal with No Added Sugar Claim. Nutrients 2018;10. doi:10.3390/nu10040435. [Epub ahead of print: 30 Mar 2018] 